\title{
Toward an Ecological Bioethics
}

\section{Nicolae Morar \& Joshua August Skorburg}

To cite this article: Nicolae Morar \& Joshua August Skorburg (2016) Toward an Ecological Bioethics, The American Journal of Bioethics, 16:5, 35-37, DOI: 10.1080/15265161.2016.1159756

To link to this article: http://dx.doi.org/10.1080/15265161.2016.1159756

\section{曲 Published online: 25 Apr 2016.}

Submit your article to this journal

LII Article views: 71

Q View related articles $\sqsubset$

View Crossmark data \lceil 
understanding, also in a health care context. It implies that biases can best be tested and-if necessary-corrected through dialogical inquiry rather than, for instance, by providing the patient with more information.

\section{REFERENCES}

Blumenthal-Barby, J. S. 2016. Biases and heuristics in decision making and their impact on autonomy. American Journal of Bioethics 16(5): 5-15.

Gadamer, H.-G. 1960 1994. Truth and method, trans. J. Weinsheimer and D. G. Marshall. New York, NY: Continuum.
Mackenzie, C., and N. Stoljar, eds. 2000. Relational autonomy. Oxford, UK: Oxford University Press.

Nagel, T. 1986. The view from nowhere. Oxford, UK: Oxford University Press

Widdershoven, G. A., and T. Abma. 2007. Hermeneutic ethics between practice and theory. In Principles of health care ethics, ed. R. E. Ashcroft, A Dawson, H. Draper, and J. R. McMillan, 2nd ed., 215-21. Chichester, UK: John Wiley, Sons Ltd.

Widdershoven, G., G. Meynen, and D. Denys. 2015. Autonomy in predictive brain implants: The importance of embodiment and dialogue. AJOB Neuroscience 6(4): 16-18.

\section{Toward an Ecological Bioethics}

\section{Nicolae Morar, University of Oregon \\ Joshua August Skorburg, University of Oregon}

Recent advancements in social psychology, behavioral economics, and even microbial biology have provided a new impetus for numerous philosophers and bioethicists to reassess some of the central concepts that inform their worldviews and value systems (Beever and Morar 2016).

The outcome of such reevaluations is especially important when it directly relates to medical practices and to fundamental concepts that shape the ethical conditions for a robust doctor-patient relationship. In this sense, Blumenthal-Barby's (2016) article not only inscribes itself in the process of a bioethical reexamination coming from the cognitive sciences and behavioral economics (Morar and Washington Forthcoming), but also, given the cumulative effect of the view of the mind that emerges, it adds a significant contribution to this urgent and much needed dialogue. We certainly recognize the tremendous benefits of such an interdisciplinary approach to bioethics, and we use this opportunity to open a productive discussion about how to frame the relationship between the social sciences and bioethics.

We raise two interrelated worries about the target article: (1) The author's operative concept of a bias might limit the range of answers that can be given to the "where do we go from here?" question in the article's conclusion. (2) The author's premises-and the picture of the mind that emerges from them-might support a more radical conclusion about autonomy than the author seems to draw. Both of these worries highlight the importance of bringing more ecologically oriented approaches into the debate.

\section{TWO WORRIES}

First, we believe that how one defines the concepts of heuristics and biases will have important consequences for how we answer the "where do we go from here?" question. We're concerned that the author's working definition is rather one-sided and almost always has a negative valence.

We do not wish to deny that heuristics and resulting biases can lead to negative outcomes or even differences in medical treatment (Morar and Washington Forthcoming). They surely can. It would be misleading, however, to suggest that heuristics and resulting biases are always inaccurate, harmful, or problematic. To be fair, the author does mention in passing that "heuristics and resulting biases might, in some cases or in some ways, help people understand the nature of an action and its consequences" (10). Still, we find the omission of a more detailed, positive account troubling.

Such a positive account can be found in Gerd Gigerenzer and colleagues' research on the "less is more" effect. For example, in Goldstein and Gigerenzer's (2002) work on the recognition heuristic, they showed that Germans were better than Americans at judging which of two large American cities was larger, and Americans were better than Germans at judging which of two large German cities was larger. Why? It is complicated, but in part, it seems that Americans were less familiar with German cities (and Germans less familiar with American cities) and they were able to infer that the city they recognized was larger than the city they didn't recognize. In this context, having less information and less knowledge actually led to better and more accurate guesses. Importantly, these effects are not

Author names are listed in alphabetical order, which reflects equal contribution to the authorship of the article.

Address correspondence to Nicolae Morar, Department of Philosophy \& the Environmental Studies Program, 1295 University of Oregon, University of Oregon, Eugene, OR 97403, USA. E-mail: nmorar@uoregon.edu 
limited to the recognition heuristic (e.g., Beaman et al. 2010).

More to the point, Gigerenzer and Todd open their (1999) Simple Heuristics That Make us Smart in a similar vein by claiming that the simple three-step decision for assessing risk of heart attack victims (Is systolic blood pressure less than 91? Is age less than 62.5? Is sinus tachycardia present?) is "more accurate in classifying heart attack patients according to risk status than are some rather complex statistical classification methods" (4-5). If this is on the right track, then the use of some heuristics might sometimes lead to biases (e.g., only paying attention blood pressure, age, etc.) that produce better, more desirable outcomes.

We think it is crucially important to take seriously this positive account, so as to keep options open for co-opting and exploiting the use of heuristics and resulting biases, much in the way the "nudge" approach cited by the author seems to require.

Our second worry similarly relates to the nature of biases, and what we might call their cumulative effect. Several psychological models have tried to provide an explanation for such cognitive processes that seem to have a robust influence on our behavior. Whether one appeals to singleprocess models (Olson and Fazio 2009), dual-process models (Gawronski and Bondehausen 2011), or multisystem models from neuroanatomy and neuroscience (Amodio and Ratner 2011), it seems that some of the features that such cognitive mechanisms consist in are impulsive, rigid, nearly automatic associations. Those cognitive mechanisms tend to function under our conscious awareness, and thus, we seem to be limited in our capacity to control or to alter them. Here, we are primarily worried that the author fails to fully appreciate the cumulative effect of the view of human cognition that emerges. Once this view is properly acknowledged, serious questions will remain about how much of the notion of autonomy can be salvaged.

We think that the most important aspect of the article is its synoptic view of the cognitive biases that potentially impact the exercise of autonomy in a medical context. It is this very same aspect, however, that is also the most troubling. We agree with the author that "they [heuristics and biases] are, after all, built in facts about our psychological tendencies" (13). The catalog of 19 biases and heuristics further attests to this fact, and we see no reason to believe the list won't expand in the future. We have to wonder, then: If this view of the mind is on the right track, what's going to be left of autonomy? It seems that given the author's premises, a skeptical or eliminativist conclusion threatens: Given the ubiquity of heuristics and resulting biases in human cognition, perhaps the traditional notion of autonomy as envisaged by philosophers just isn't the sort of thing creatures like us can (reliably) attain.

\section{FUTURE DIRECTIONS}

The one-sidedness worry and the cumulative effect worry come together now, because they are both concerns about how we ought to think about biases. The way we think of biases, in turn, informs the sorts of answers we can give to the question "where do we go from here?" Depending on the operative definition, some solutions will emerge as being more attractive than others.

If heuristics and biases are rendered as cognitive blemishes, then it of course makes sense to talk about removing them, or at least counteracting them. But if heuristics and biases are rendered as, at least sometimes, useful and effective (after all, is it such a bad thing that fear biases our attention to nearby threats?), then it would make sense to talk about exploiting them to our advantage, or at least, not counteracting them.

Unless we start the conversation in this way, it is particularly difficult to propose bioethical and policy-oriented amendments, since one would not know how and where to even measure the success of such procedures. Painting all heuristics as impediments to autonomy, for example, would stop us short of thinking of how to integrate them into a more sensitive conception of human cognition and autonomous behavior. Moreover, underplaying the cumulative effect of such a catalog of human biases is detrimental to our intervention strategies, since it would seem that some strategies (i.e., removal strategies) are equally useful in comparison to more ecologically oriented ones (e.g., Clark 2007).

The risk of decoupling these two points and of ignoring the empirical literature on interventions to reduce bias effects on our behavior is substantial since bioethicists, in particular, should strongly resist the temptation of producing "just-so stories" about eliminating, mitigating, and countering biases and heuristics.

Given all of this, we believe that the next set of research questions becomes: What version of autonomy can accommodate the fact that most of the time, for better or worse, human cognition employs heuristics and biases? If we are better at noticing these biases in others than in ourselves, does this point toward anti-individualism about autonomy? What version of autonomy can accommodate the fact that, for better or worse, features of the environment (often outside of an agent's control) form constitutive components of heuristics and biases (e.g., Alfano and Skorburg Forthcoming)? Only by taking seriously the cumulative and constitutive dimensions of heuristics and biases can we see why the question is not primarily about getting rid of them, but of learning how to harness them in accordance with our values. Hence, the need for an ecological bioethics that looks at how we can design our environments so that they promote rather than undermine our values.

\section{REFERENCES}

Alfano, M., and J. A. Skorburg. Forthcoming. Extended knowledge, the recognition heuristic, and epistemic injustice. In Extended knowledge, ed. D. Pritchard et al. Oxford, UK: Oxford University Press. 
Amodio, D., and K. Ratner. 2011. A memory systems model of implicit social cognition. Current Directions in Psychological Science 20(3): $143-48$

Beaman, C. P., et al. 2010. Less-is-more effects without the recognition heuristic. Judgment and Decision-Making 5 (4):258-271.

Beever, J., and N. Morar. 2016. The porosity of autonomy: Social and biological constitution of the patient in biomedicine. American Journal of Bioethics 16(2): 34-45.

Blumenthal-Barby, J. S. 2016. Biases and heuristics in decision making and their impact on autonomy. American Journal of Bioethics 16(5): 5-15.

Clark, A. 2007. Soft selves and ecological control. In Distributed cognition and the will: Individual volition and social context, ed. D. Ross, D. Spurrett, H. Kincaid, and G. L. Stephens, 101-22. Cambridge, MA: MIT Press
Gawronski, B., and G. Bodenhausen. 2011. The associative-propositional evaluation model: Theory, evidence, and open questions. Advances in Experimental Social Psychology 44:59-127.

Goldstein, D., and G. Gigerenzer. 2002. Models of ecological rationality: The recognition heuristic. Psychological Review 109(1): 75-90

Gigerenzer, G., P. Todd, and ABC Research Group. 1999. Simple heuristics that make us smart. Oxford, UK: Oxford University Press.

Morar, N., and N. Washington. Forthcoming. Implicit cognition and gifts: How does social psychology help us think differently about medical practice? Hastings Center Report

Olson, M., and R. Fazio. 2009. Implicit and explicit measures of attitudes: The perspective of the MODE model. In Attitudes: Insights from the new implicit measures, ed. R. Petty, R. Fazio, and P. Briñol, 19-63. Hillsdale, NJ: Lawrence Erlbaum Associates. 